\title{
Correction to: Dynamical system analysis of interacting models
}

\section{S. Carneiro ${ }^{1}$ (D) H. A. Borges ${ }^{2}$}

Published online: 19 September 2018

c) Springer Science+Business Media, LLC, part of Springer Nature 2018

\section{Correction to: Gen Relativ Gravit (2018) 50:1 https://doi.org/10.1007/s10714-017-2322-8}

Unfortunately, there are typos in Eqs. (20) and (22), as well as in the line following Eq. (27). The results and conclusions were not affected. The correct equations are

$$
\begin{gathered}
\left(\rho_{i} \vartheta_{i}\right)^{\prime}+4 \mathcal{H} \rho_{i} \vartheta_{i}-\rho_{i} k^{2} \Phi=-a Q_{i} \vartheta_{i}, \\
\vartheta_{i}^{\prime}+\mathcal{H} \vartheta_{i}=k^{2} \Phi .
\end{gathered}
$$

In the line following Eq. (27), the correct sentence is: "If we now take $Q_{i} / \rho_{i}=-\Gamma \ldots$..'

The original article can be found online at https://doi.org/10.1007/s10714-017-2322-8.

S. Carneiro

saulo.carneiro.ufba@gmail.com

1 Instituto de Física Gleb Wataghin, UNICAMP, Campinas, SP 13083-970, Brazil

2 Instituto de Física, Universidade Federal da Bahia, Salvador, BA 40210-340, Brazil 